\title{
Ernest Pépin, Le Bel incendie
}

\section{Emanuela Cacchioli}

\section{(2) OpenEdition}

\section{Journals}

\section{Edizione digitale}

URL: https://journals.openedition.org/studifrancesi/3254

DOI: 10.4000/studifrancesi.3254

ISSN: 2421-5856

\section{Editore}

Rosenberg \& Sellier

\section{Edizione cartacea}

Data di pubblicazione: 1 juillet 2013

Paginazione: 500

ISSN: 0039-2944

\section{Notizia bibliografica digitale}

Emanuela Cacchioli, «Ernest Pépin, Le Bel incendie», Studi Francesi [Online], 170 (LVII | II) | 2013, online dal 30 novembre 2015, consultato il 01 février 2023. URL: http://journals.openedition.org/ studifrancesi/3254 ; DOI: https://doi.org/10.4000/studifrancesi.3254

\section{Questo documento è stato generato automaticamente il 1 février 2023}

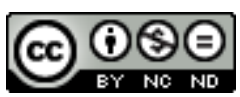

Creative Commons - Attribuzione - Non commerciale - Non opere derivate 4.0 Internazionale - CC BY NC-ND 4.0

https://creativecommons.org/licenses/by-nc-nd/4.0/ 


\title{
Ernest Pépin, Le Bel incendie
}

\author{
Emanuela Cacchioli
}

\section{NOTIZIA}

ERNEST PÉPIN, Le Bel incendie, Paris, Éditions Bruno Doucey, 2012, pp. 64.

1 L'immagine dell'incendio, che compare nel titolo della raccolta poetica dell'autore guadalupano, è da intendersi come la lava incandescente del vulcano: una forza oscura, incontenibile che, di tanto in tanto, si sprigiona e avvolge il pendio della montagna che la contiene. La poesia per Ernest Pépin consiste proprio nella capacità di avvicinarsi al magma e di dominarlo, di fissarlo sulla pagina e lasciare che scorra in modo controllato. Nella prefazione del testo, l'editore Bruno DOUCEY, sostiene che il vulcano, a cui il poeta fa riferimento, corrisponde a «[...] désir, colère, débordement, chair d'esclaves marquée au fer rouge, racines rougeoyant sous les brûlures de l'Histoire, passions souveraines, souvenirs des dieux anciens, nature imprévisible» (p. 7). Sono questi i principali temi affrontati nella raccolta e che, nelle diverse poesie, vengono associati ad un'immagine sempre differente.

2 Il volume si apre con un omaggio alla donna: Je t'ai nommée l'indienne (pp. 9-40). Da sempre attento alla figura femminile, Pépin, in questa occasione, la celebra come emblema dell'identità composita costitutiva delle popolazioni antillane. Il poeta considera la Guadalupa come crogiolo di civiltà, di lingue, di culture diverse che si sono incontrate in seguito ai fenomeni di migrazione che hanno interessato le isole caraibiche. Per quanto riguarda la Guadalupa, Pépin si sofferma su quel $30 \%$ della popolazione di origine indiana e su un particolare evento: il 24 dicembre 1854, la nave Aurélie giunse alle coste dell'isola con a bordo circa trecento lavoratori indiani da impiegare nelle piantagioni. La donna cantata dal poeta rappresenta la nascita di un'umanità che si fonda sulla diversità, sulla mescolanza di una pluralità di influssi che generano un'identità in relazione con il mondo. Non è un caso che il poeta la definisca «Femme-monde» (p. 18) in grado di fondere il dolce ricordo del paese da cui proviene con la ferita impressa dalla traversata e il segreto delle isole in cui vive. La donna è 
anche depositaria della memoria del popolo, del suo idioma ed è capace di fondare un nuovo linguaggio in grado di raccontare l'indicibile, il proibito, il dolore, ma anche il «pays de femme [...] / où la noblesse est de métisser» (p. 40).

3 La donna in quanto custode dei segreti della vita e della morte, il ricordo del passato e della tradizione, l'immagine dell'incendio che divampa la notte, sono i temi ripresi nella poesia Paroles rouges (Boula-gueule) (pp. 41-48). Nel componimento successivo, Le tambour-volant (pp. 49-53), il ritmo scandito dal tamburo, usato nelle danze tradizionali del passato, permette al poeta di incontrare la donna e, grazie alla sua mediazione, di entrare in comunicazione con l'invisibile, di rintracciare la tradizione e di esserne difensore nel tempo presente.

4 La raccolta si chiude con Le Chant du Tout-Monde (pp. 55-59), un tributo a Édouard Glissant e alla sua «écriture totale et totalement indélébile» (p. 59). Ernest Pépin completa dunque il volume con un testo che mentre stabilisce un fitto dialogo con il componimento posto in apertura, rende anche omaggio all'autore martinicano che costituisce una fonte di riferimento indiscussa per tutta la sua produzione poetica. 